University of Wollongong

Research Online

Faculty of Commerce - Papers (Archive)

Faculty of Business and Law

$1-1-2005$

\title{
Modelling the Impact of China's WTO Membership on Its Investment and Growth: A New Flexible Keynesian Approach
}

Van Hoa Tran

University of Wollongong, tvheco@uow.edu.au

Follow this and additional works at: https://ro.uow.edu.au/commpapers

Part of the Business Commons, and the Social and Behavioral Sciences Commons

\section{Recommended Citation}

Tran, Van Hoa: Modelling the Impact of China's WTO Membership on Its Investment and Growth: A New Flexible Keynesian Approach 2005, 251-265.

https://ro.uow.edu.au/commpapers/1958

Research Online is the open access institutional repository for the University of Wollongong. For further information contact the UOW Library: research-pubs@uow.edu.au 


\title{
Modelling the Impact of China's WTO Membership on Its Investment and Growth: A New Flexible Keynesian Approach
}

\author{
Abstract \\ The standard theories of economics, international finance, transnational corporations, and within the \\ accouting framework of the United Nations System of National Accounts (SNA93) or earlier stipulate that \\ investment plays a crucial role in influencing microenconomic activity, national ouput growth and \\ economic development.

\section{Keywords} \\ Modelling, Impact, China, WTO, Membership, Its, Investment, Growth, Flexible, Keynesian, Approach

\section{Disciplines} \\ Business | Social and Behavioral Sciences

\section{Publication Details} \\ Tran Van Hoa, J. (2005). Modelling the Impact of China"s WTO Membership on Its Investment and \\ Growth: A New Flexible Keynesian Approach. Contributions to Economics: WTO and World Trade \\ Challenges in a New Era, 251-265.
}




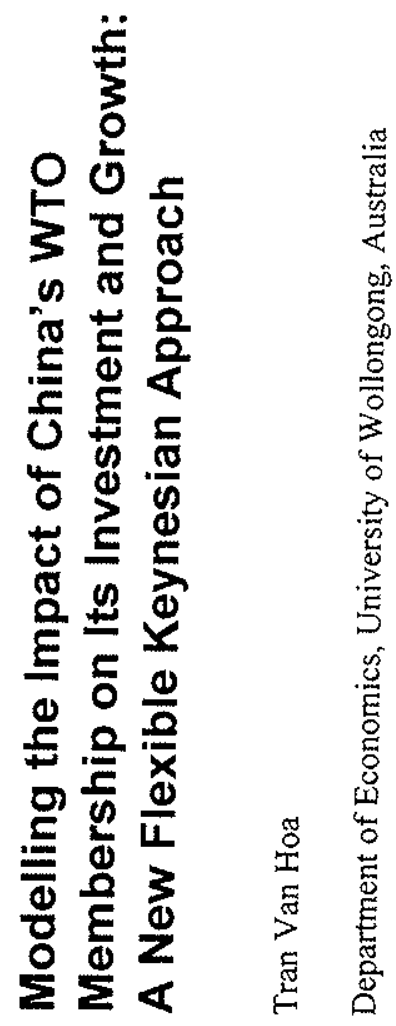

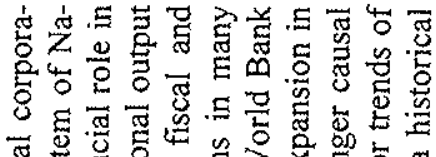

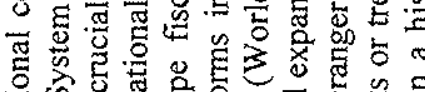
은

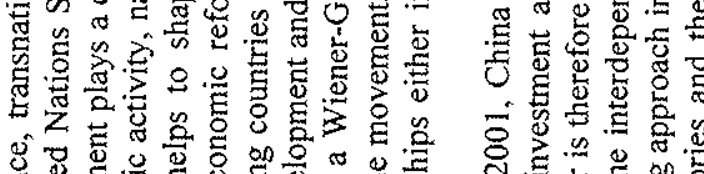

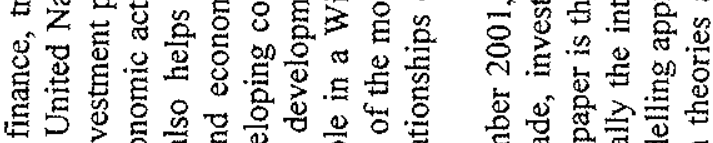

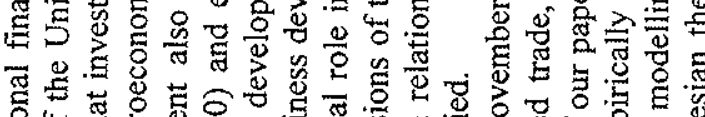

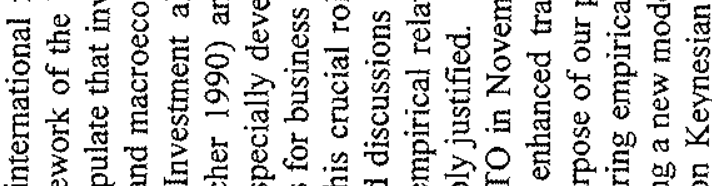

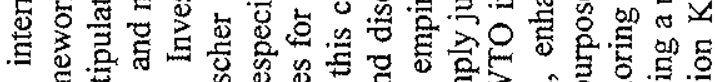

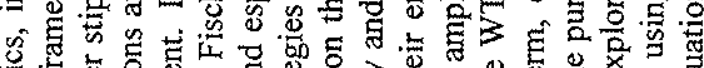

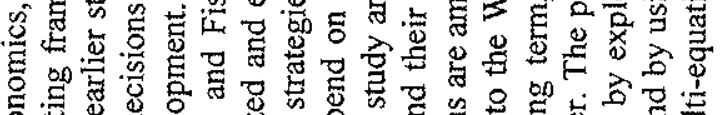

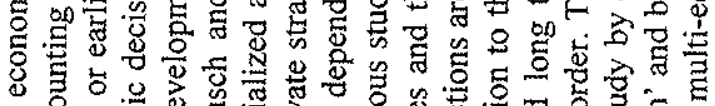

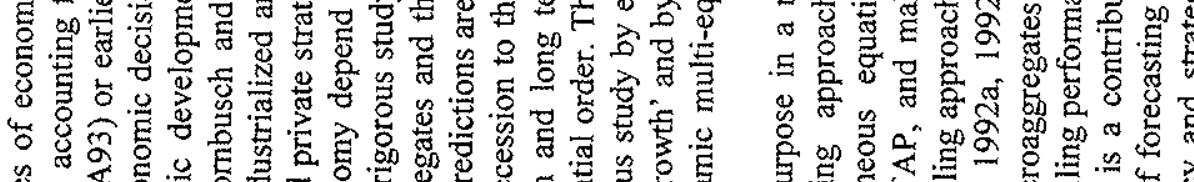

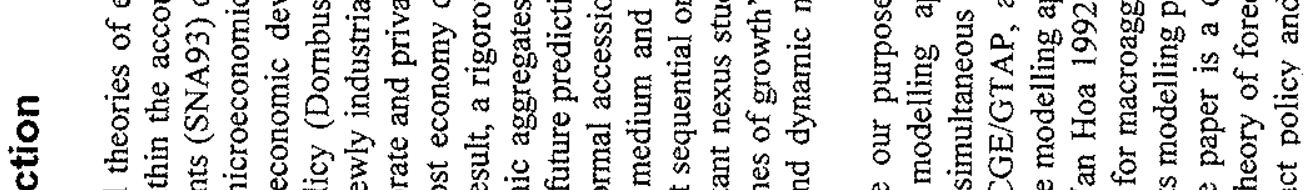

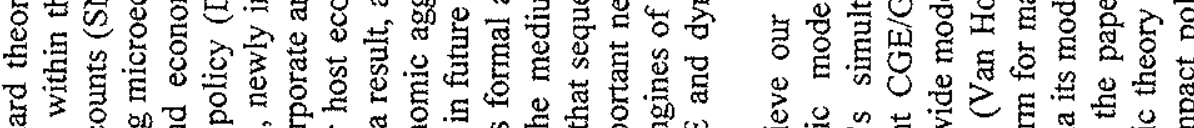

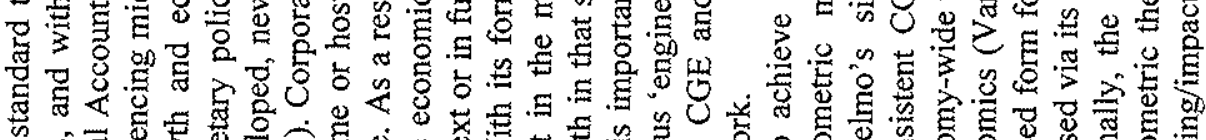

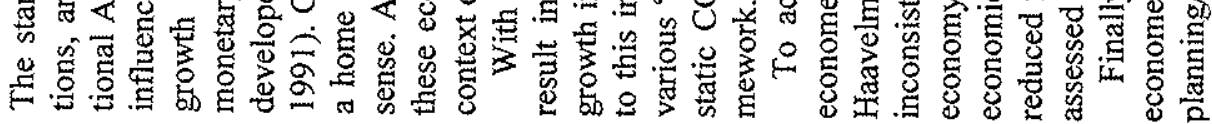

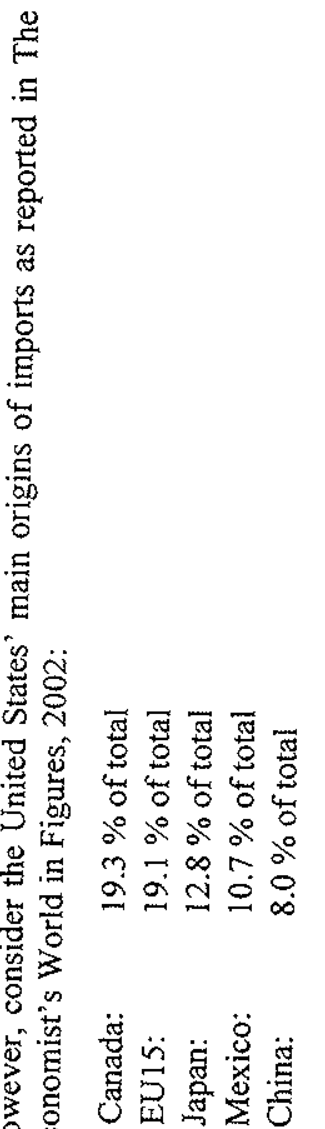

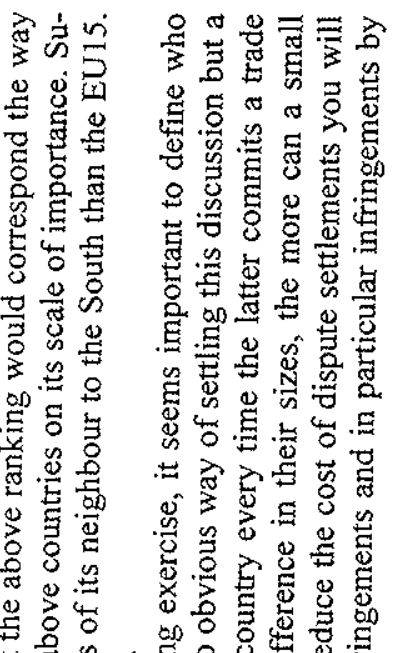

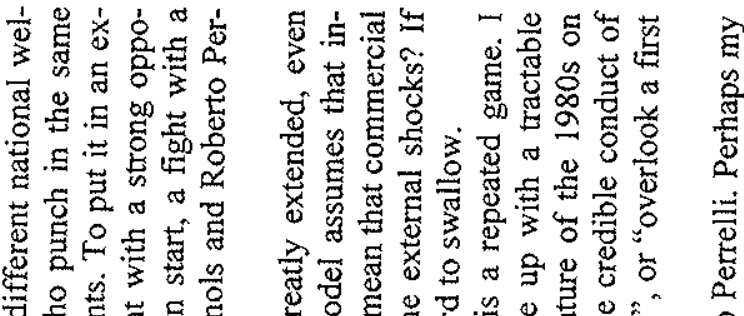

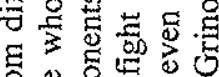

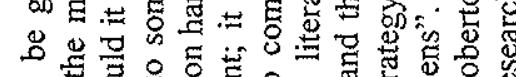

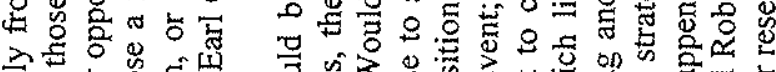

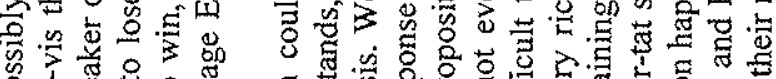

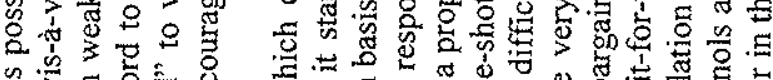

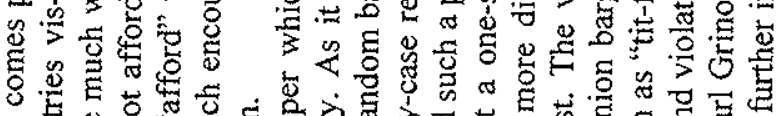

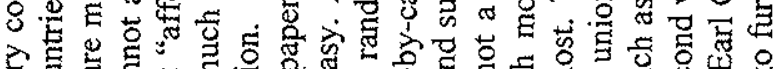

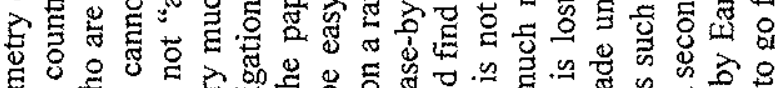

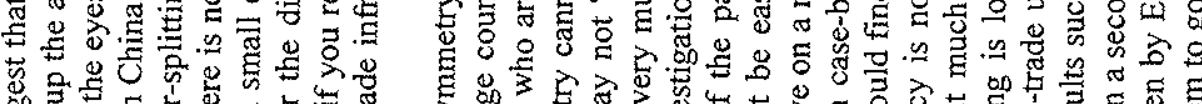

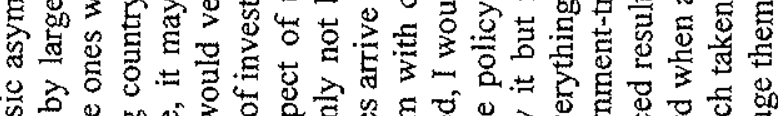
衣,

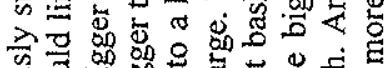

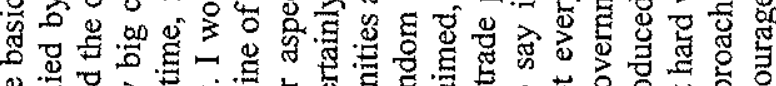

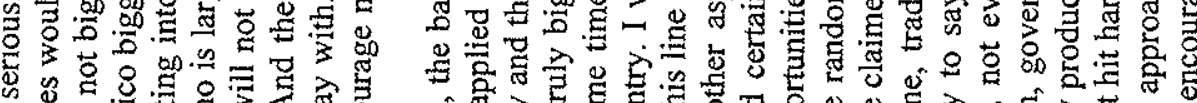

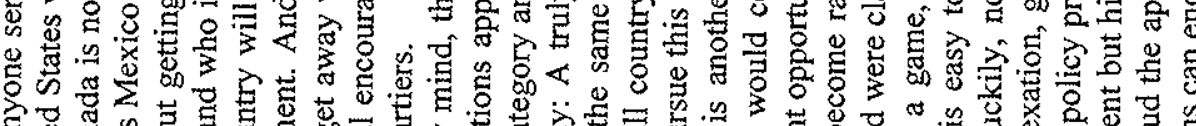

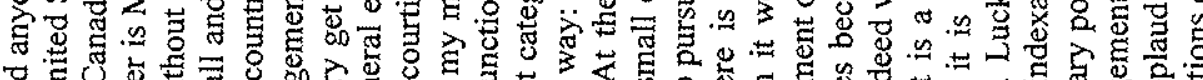
政5

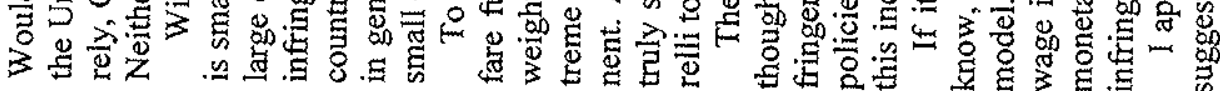




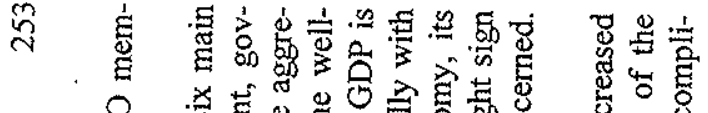

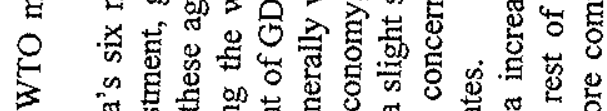

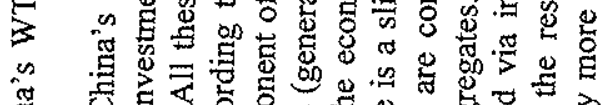

告

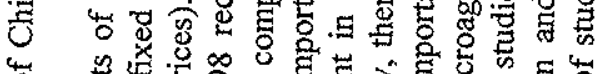

岁

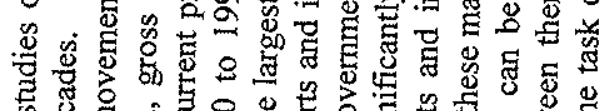

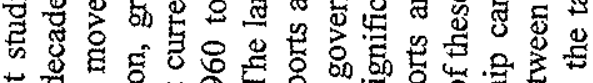

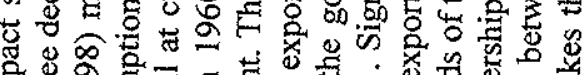

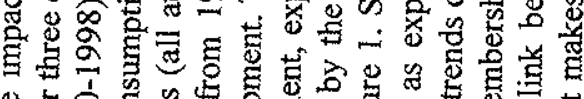

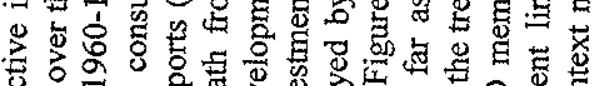

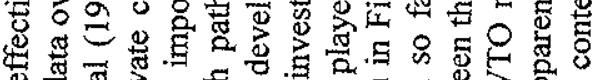

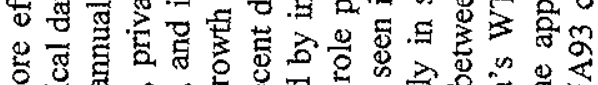

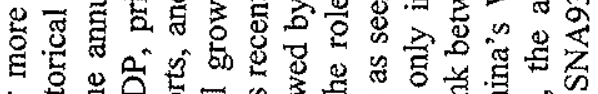

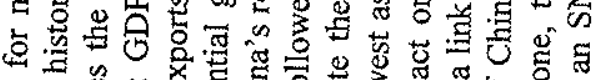

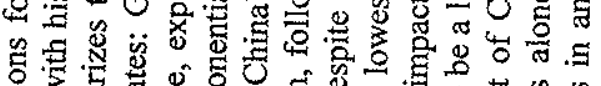

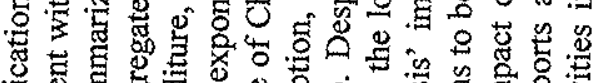

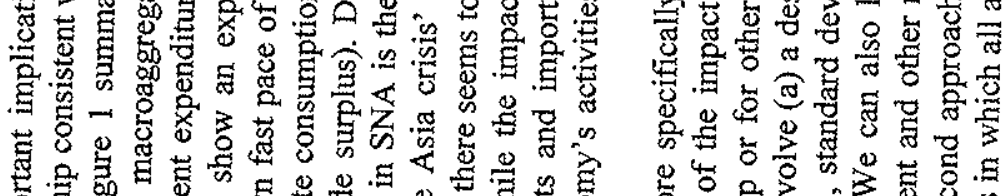

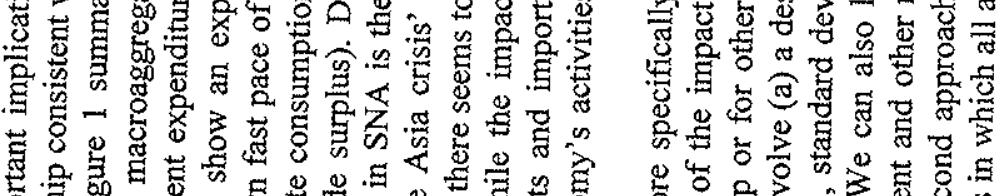

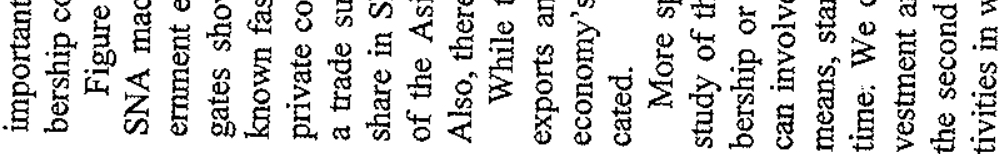

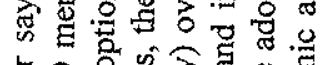

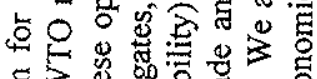

E.

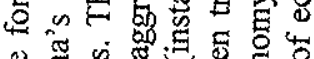

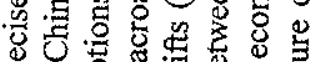

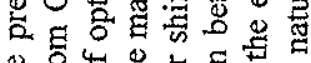

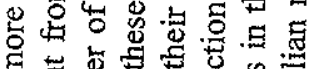

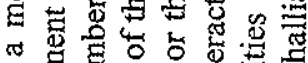

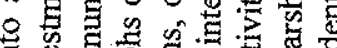

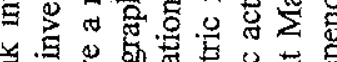

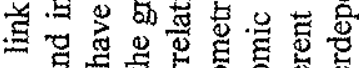
क

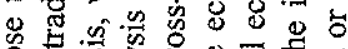

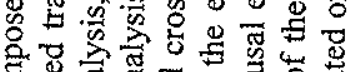

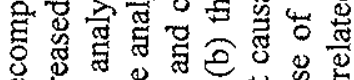

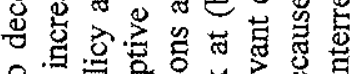

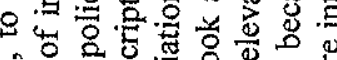
有 तु (1) . 总

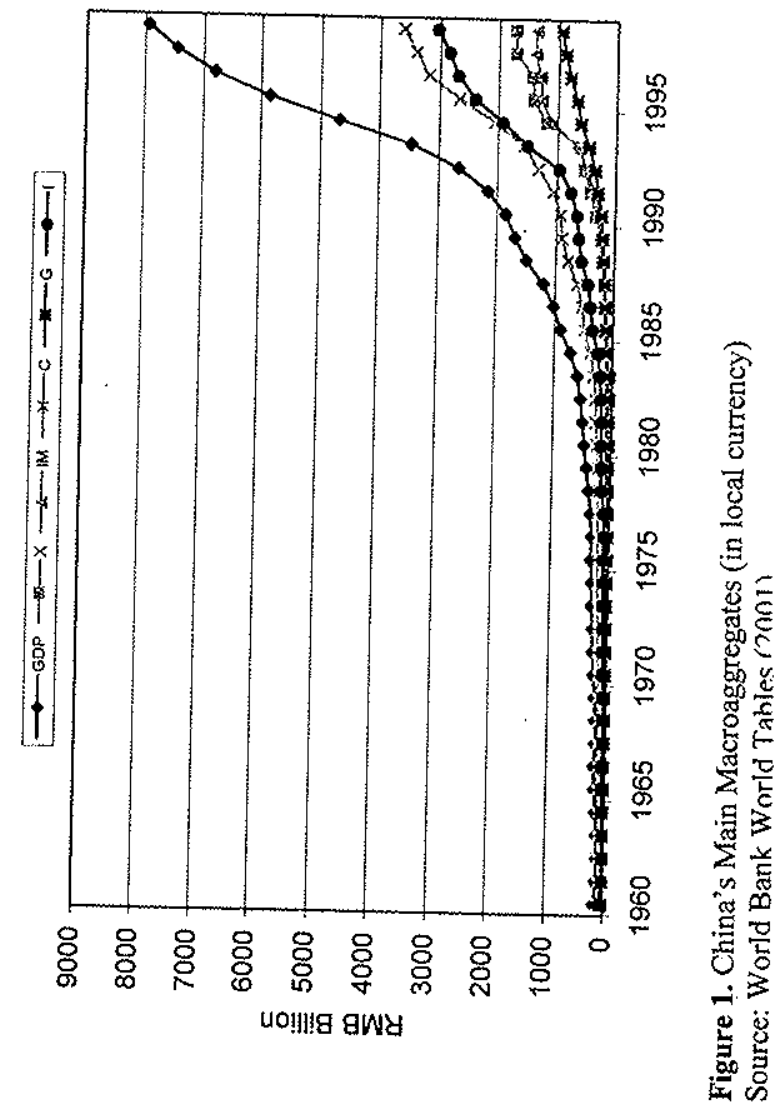

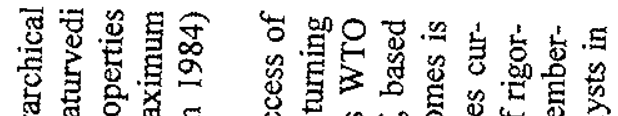

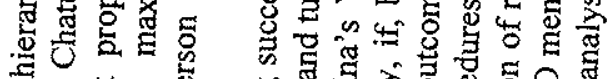

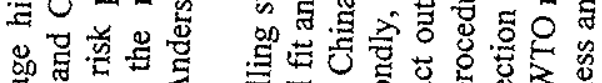

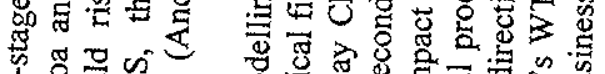

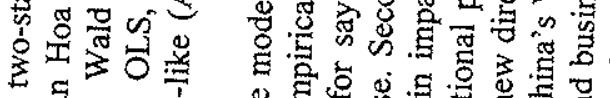

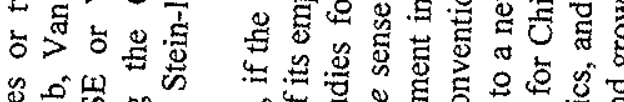

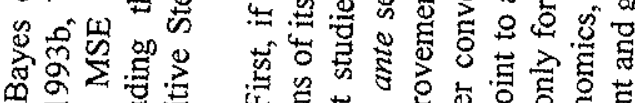

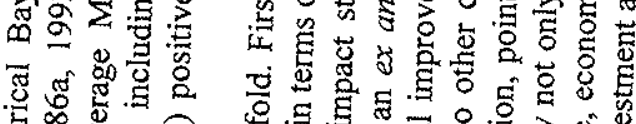

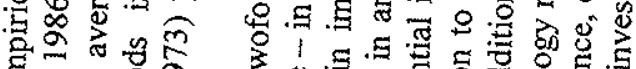

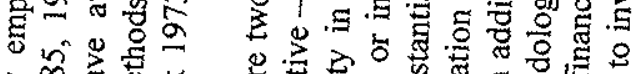

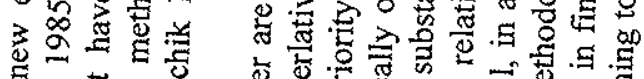

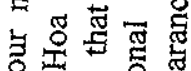

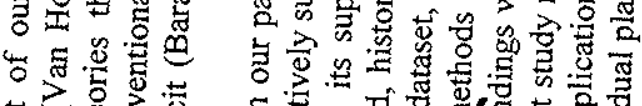

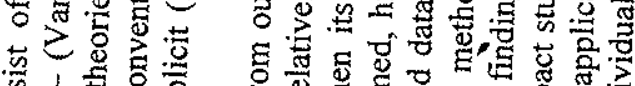

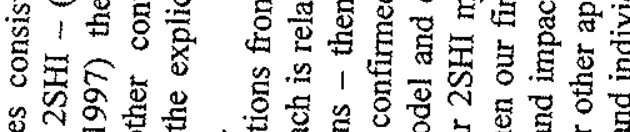

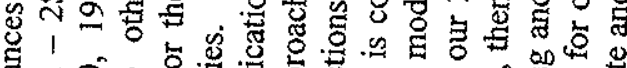

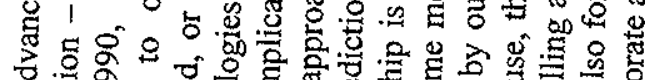

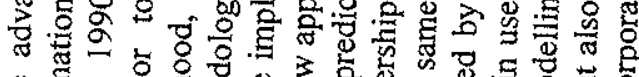

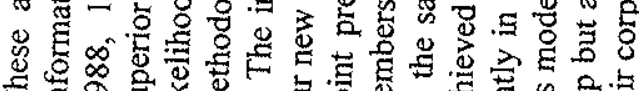

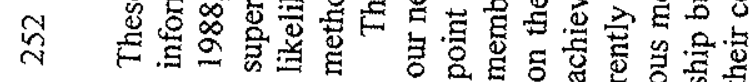

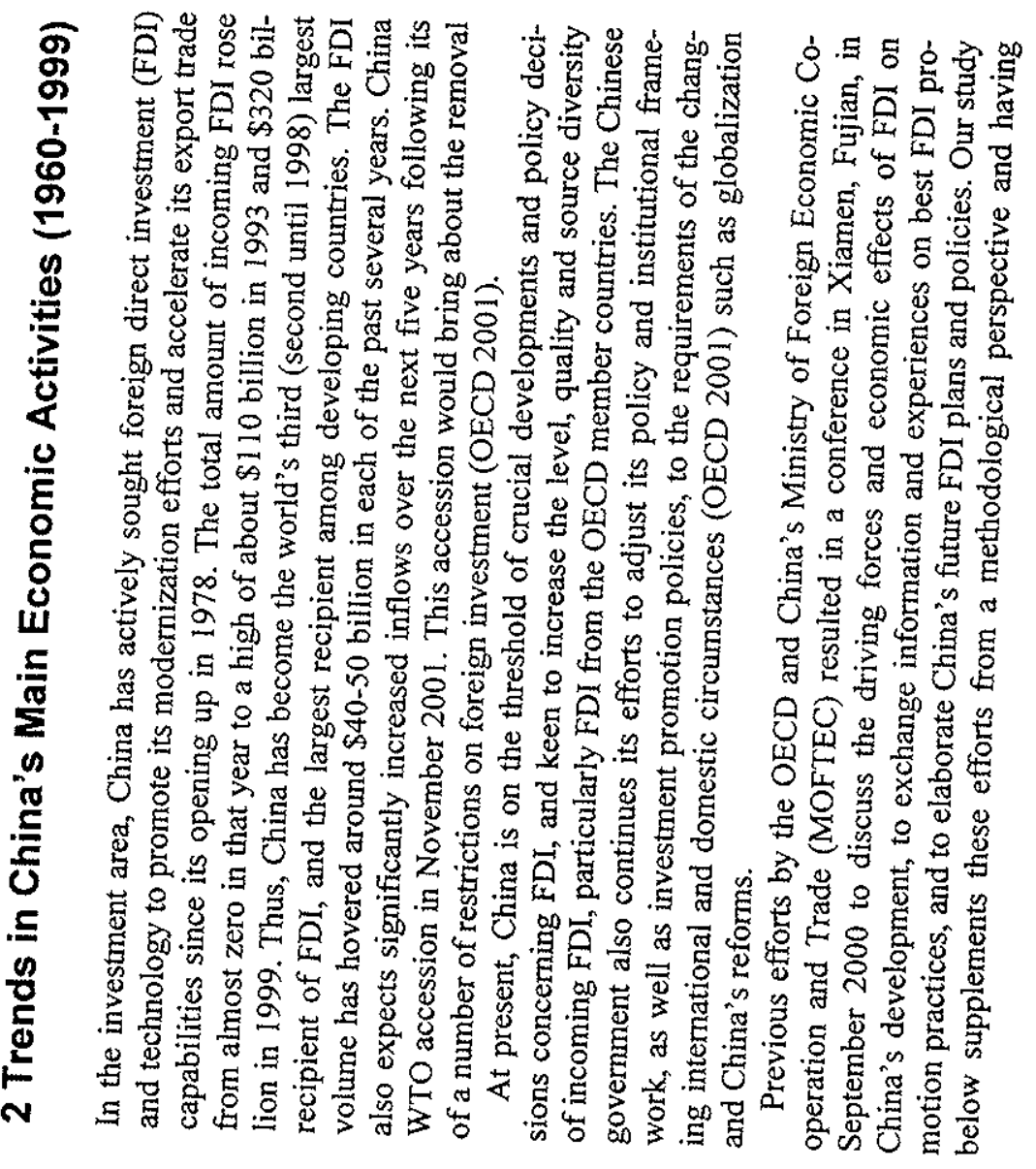




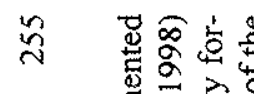

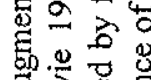

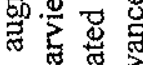

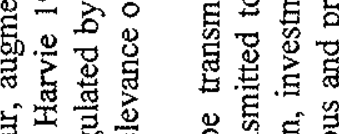

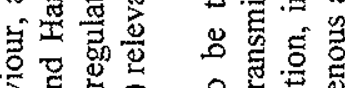

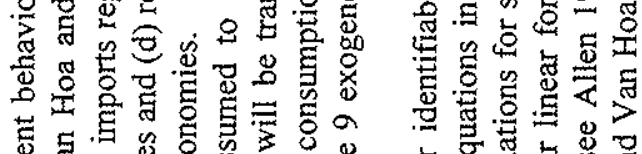

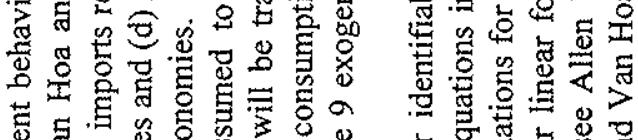

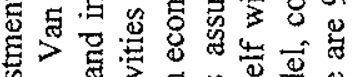

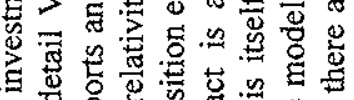

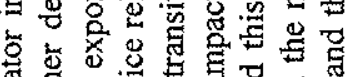

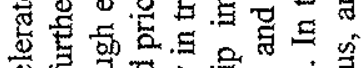

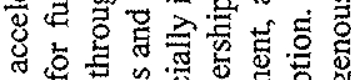

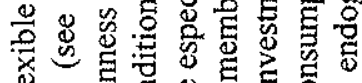

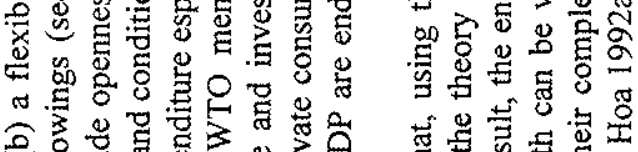

ê웝

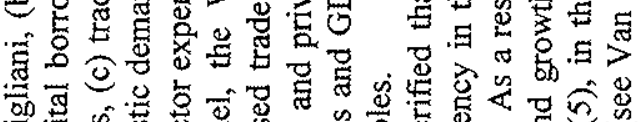

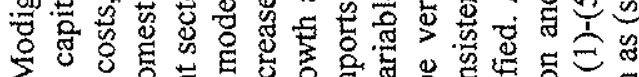

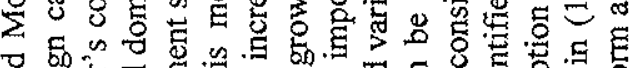

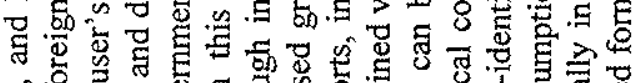

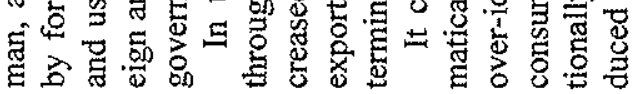

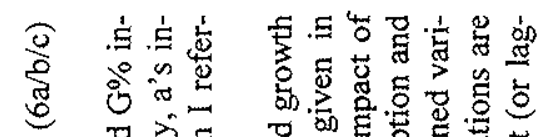

马े

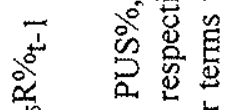

等

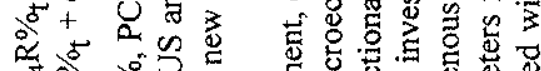

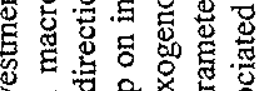

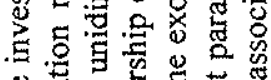

50

等

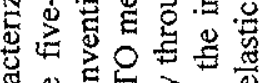

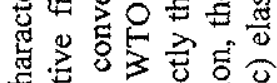

원

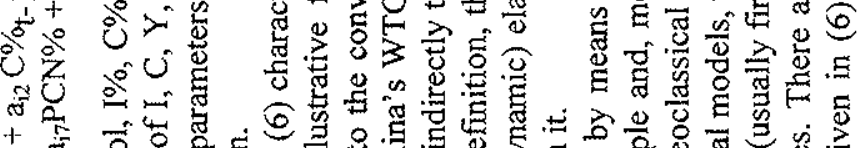

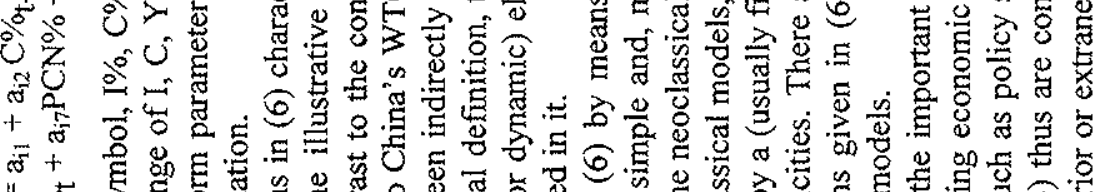
"1 席

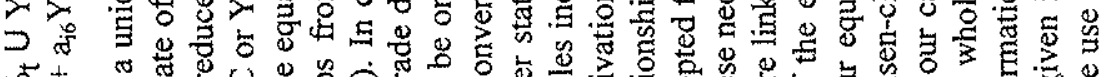
$\mathrm{O}^{+4}$.

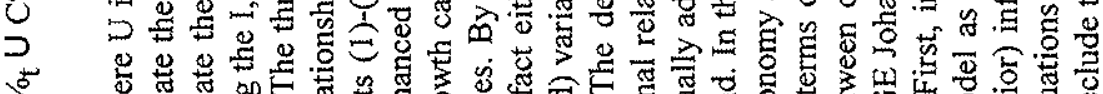

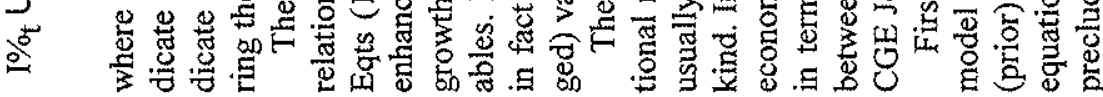

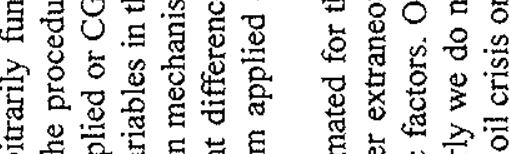

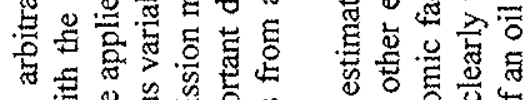

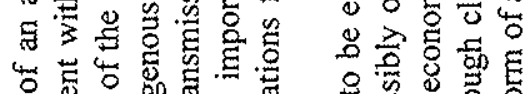

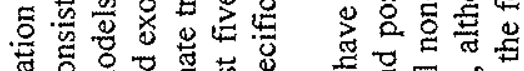
政

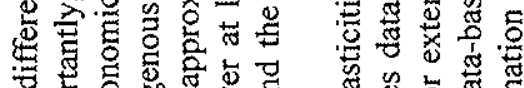
ल

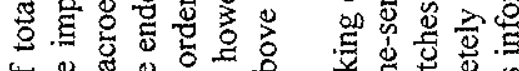

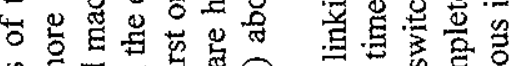

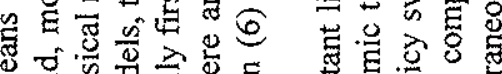

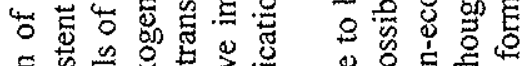




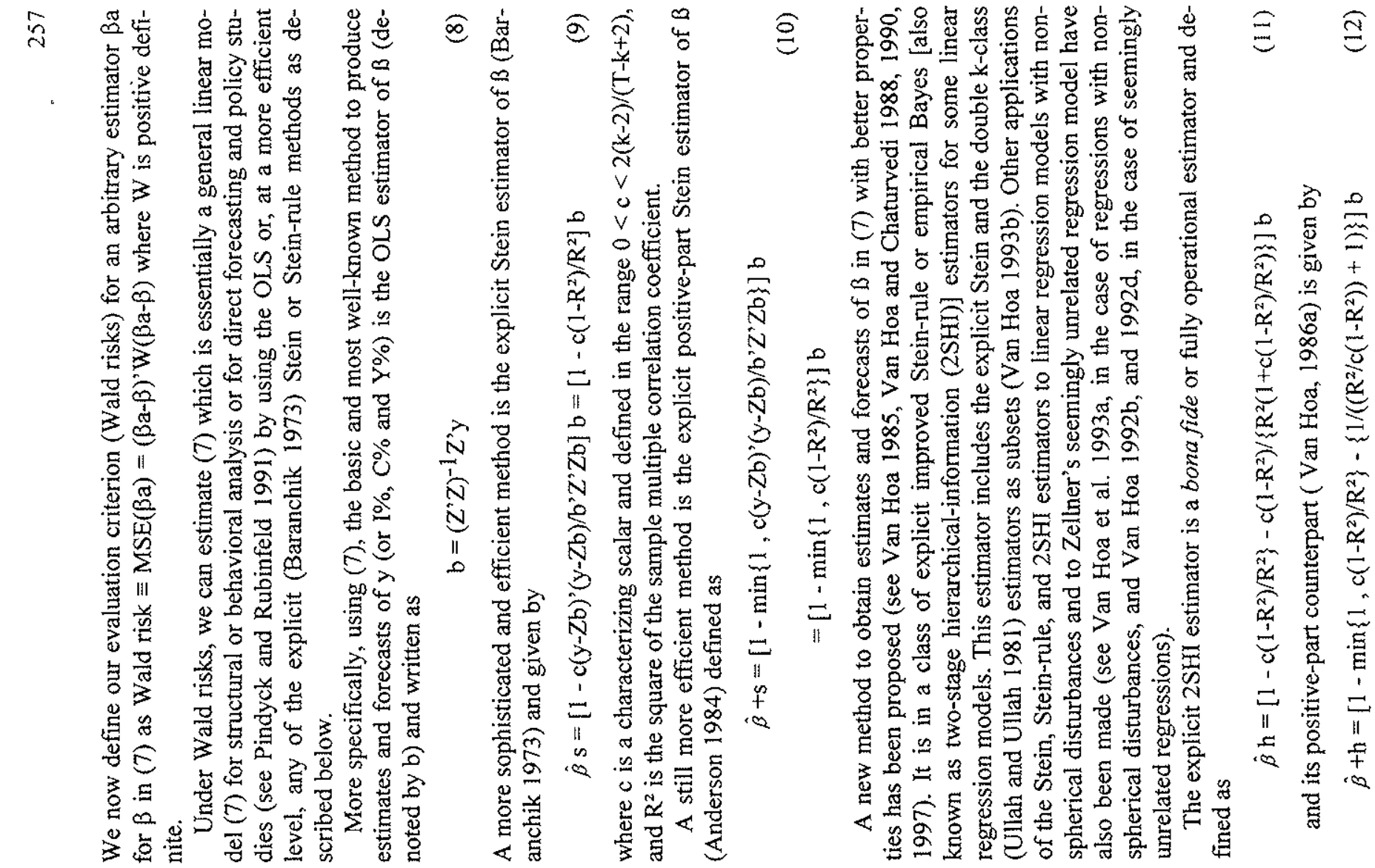

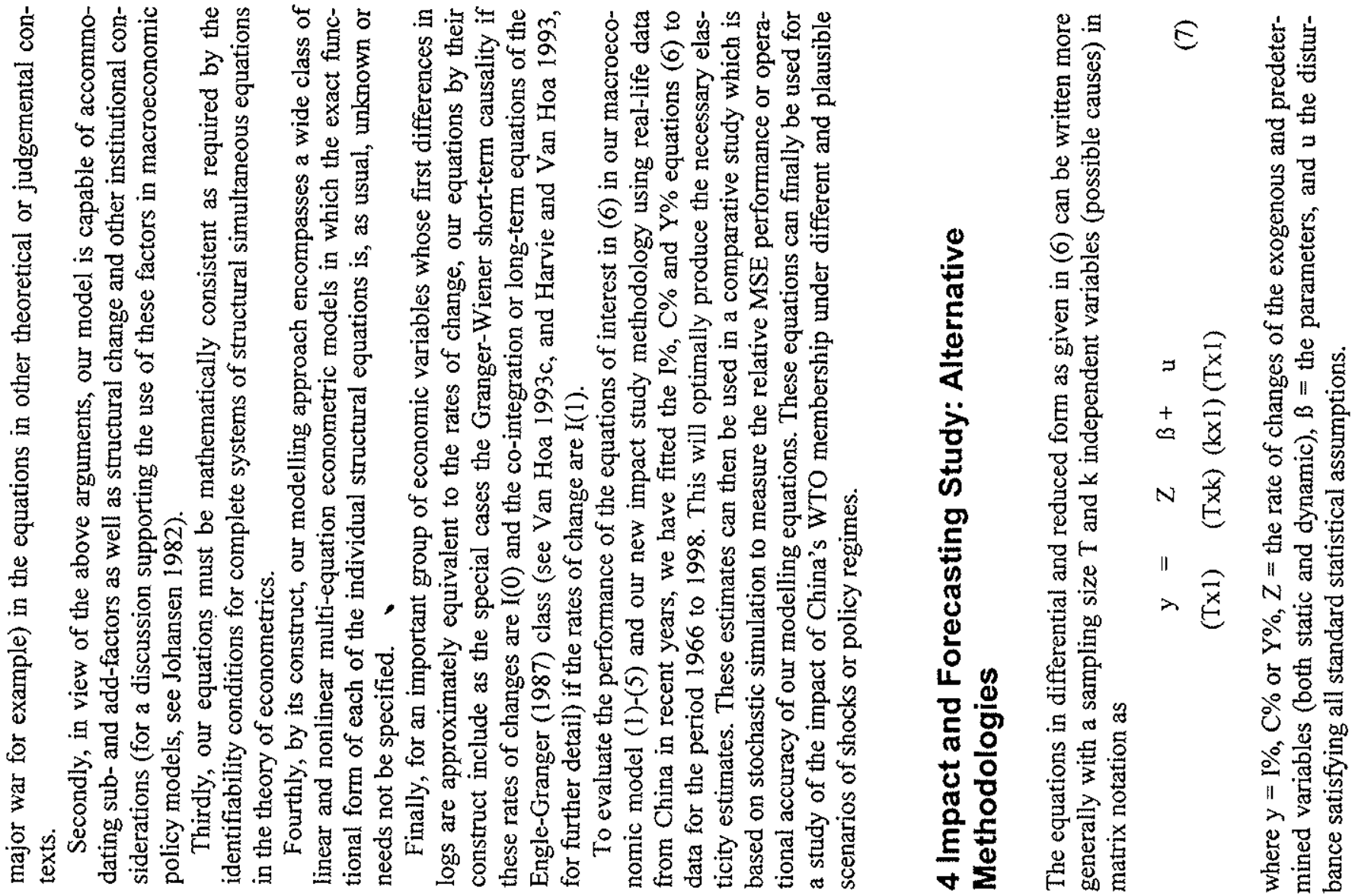




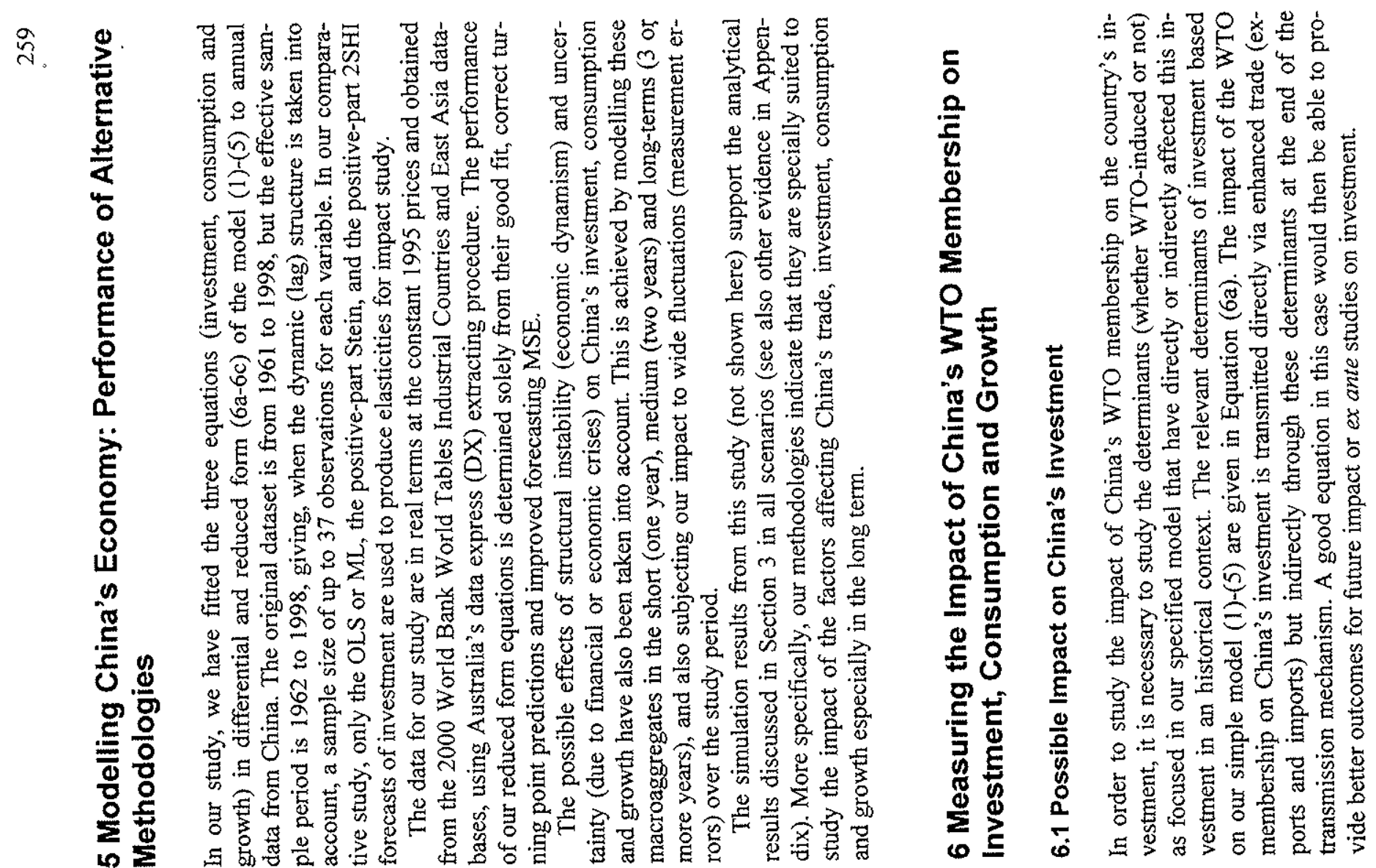

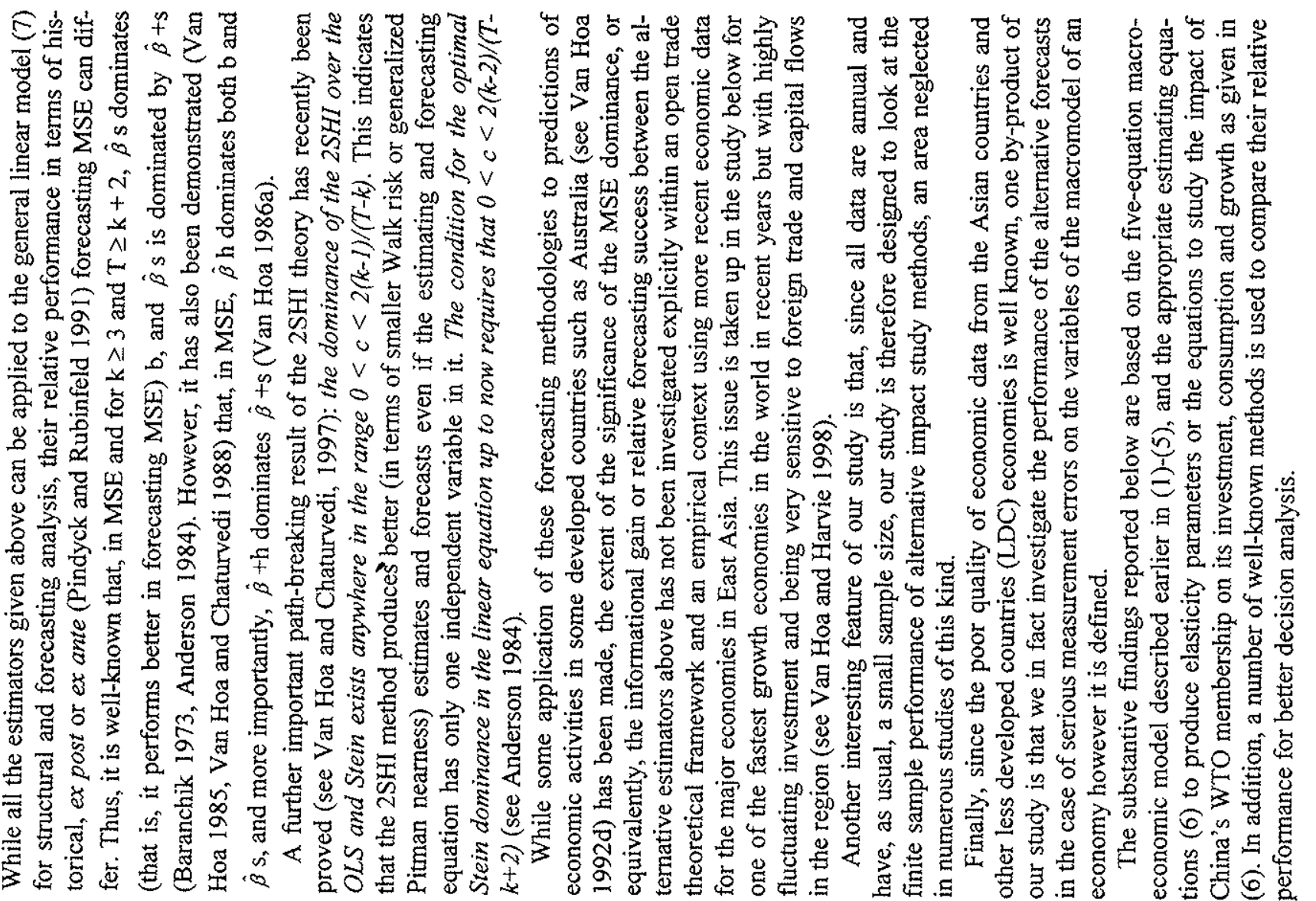


누 훙

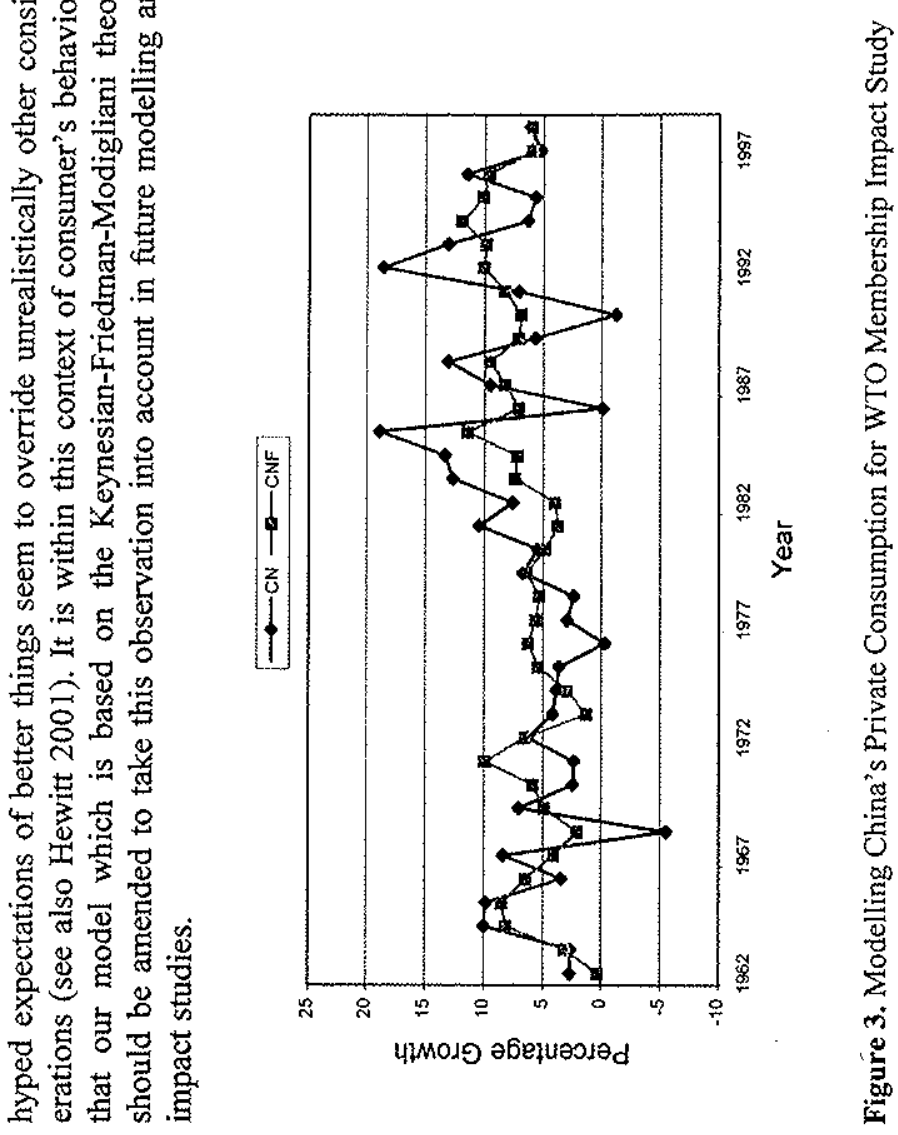

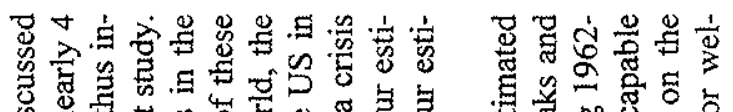

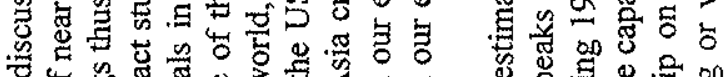

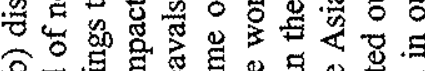

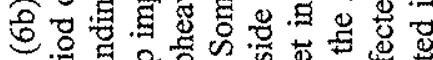

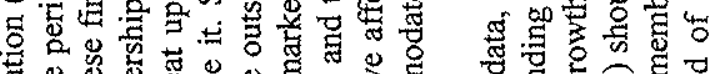

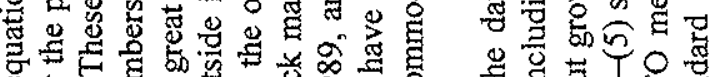

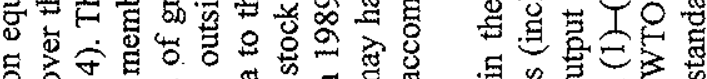

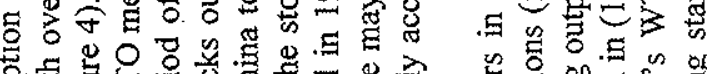

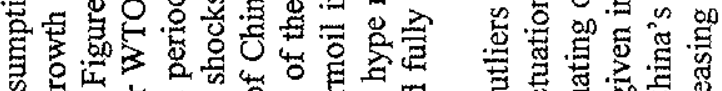

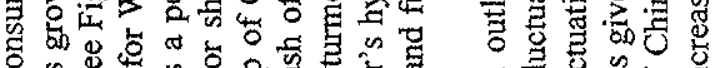

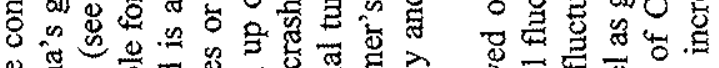

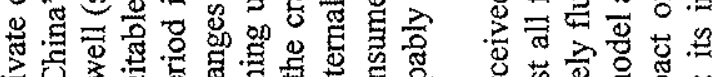

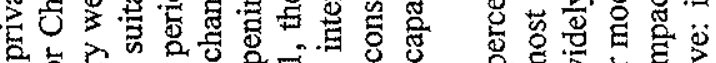

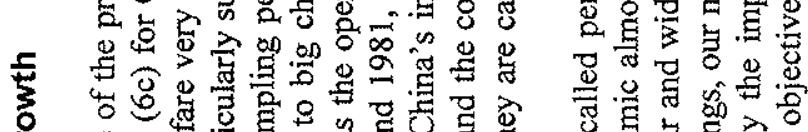

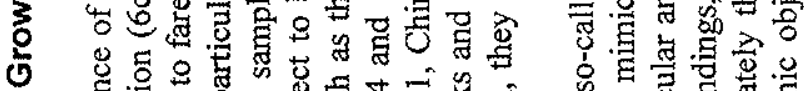

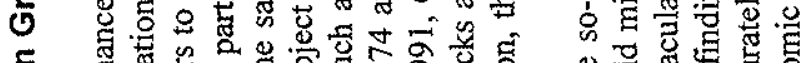

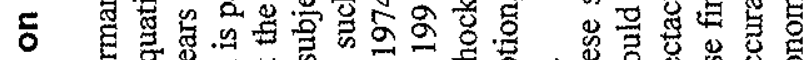

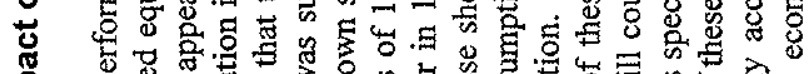

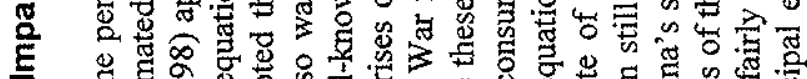

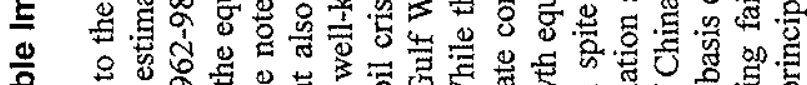

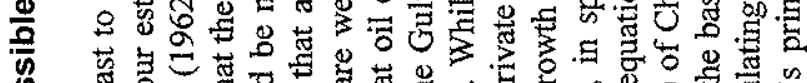
员

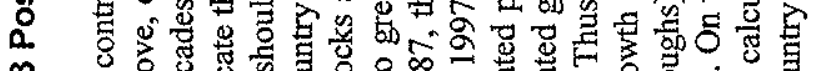

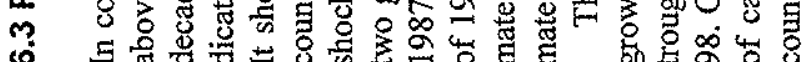

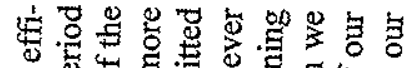

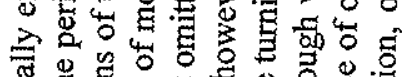

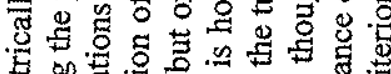

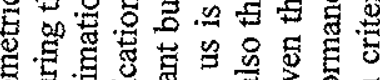

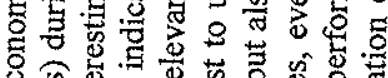
8. 万人

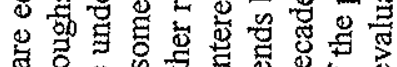
马

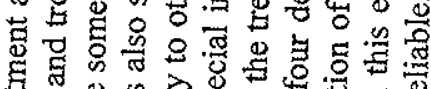

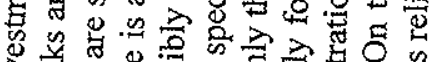

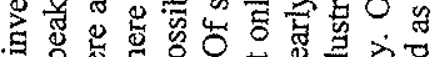

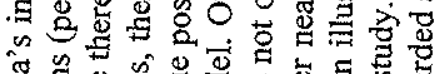

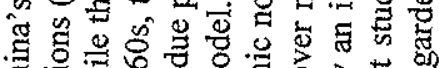

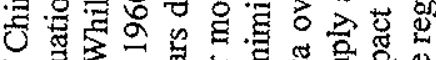

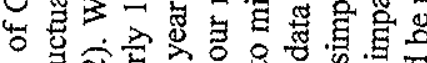
o

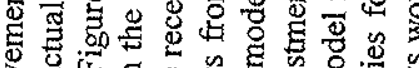

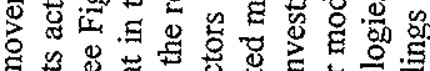

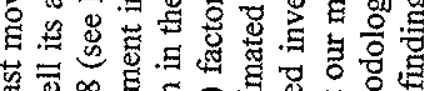

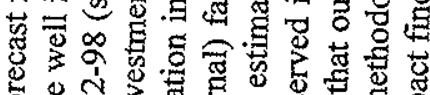

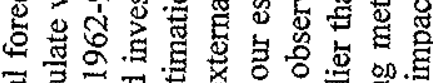
क्षे

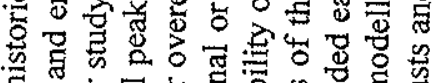

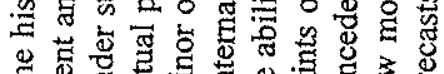

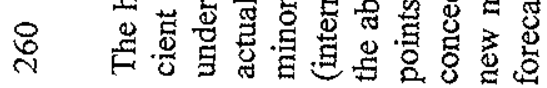

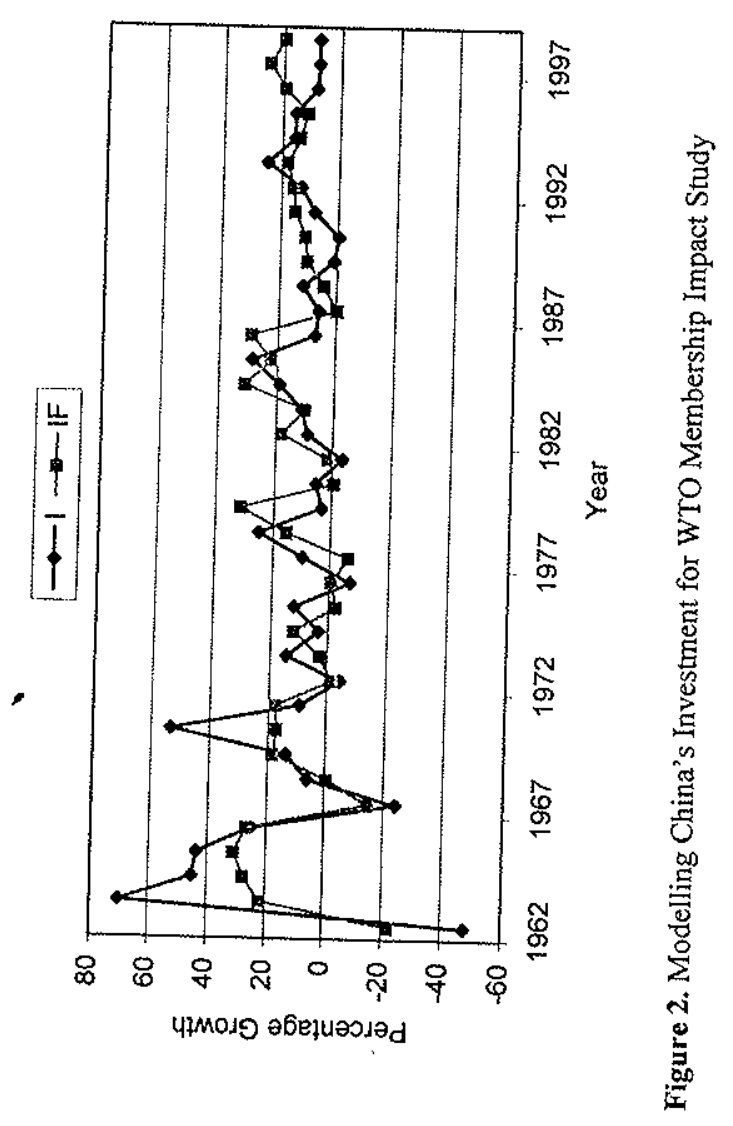

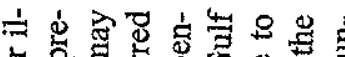

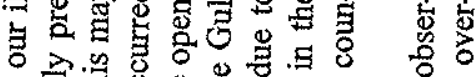

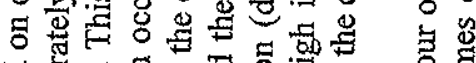
च

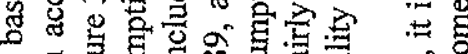

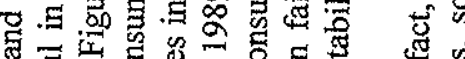

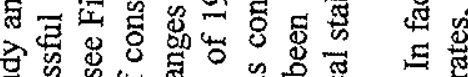

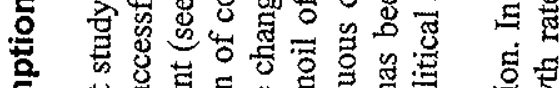

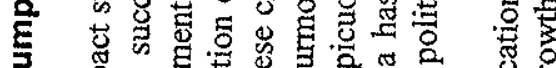

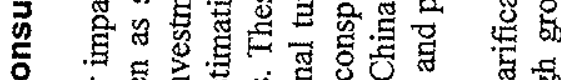

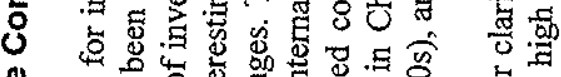

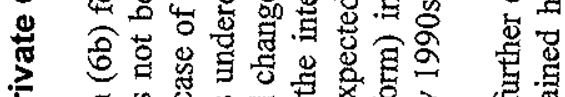

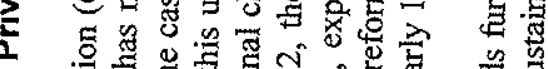

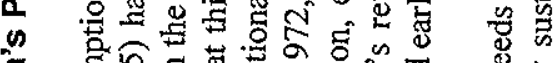

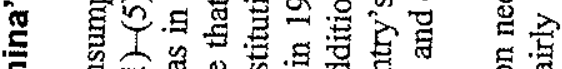

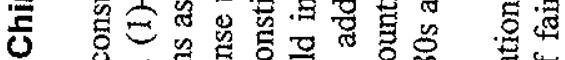

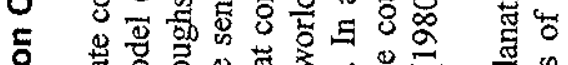

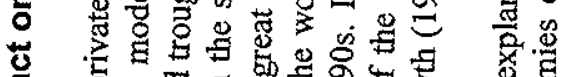
\%

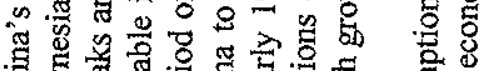

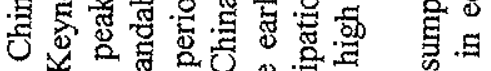
an 罂

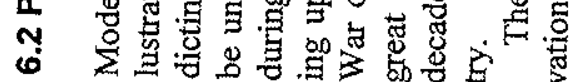




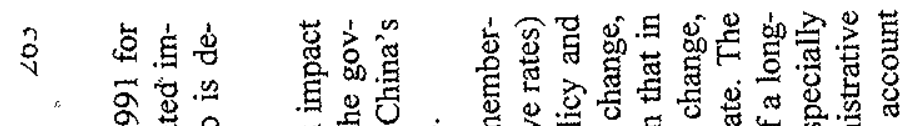

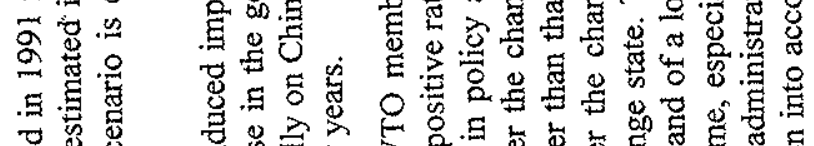

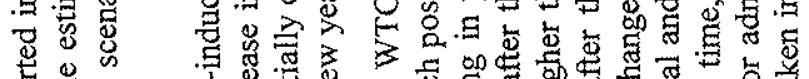

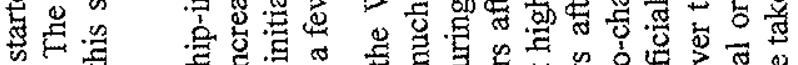

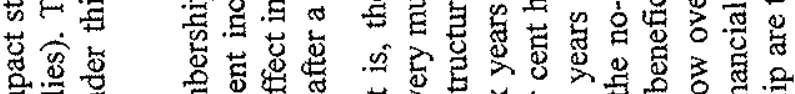

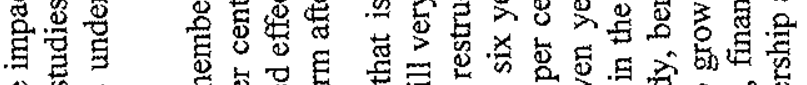

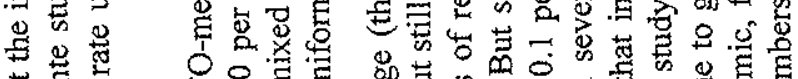

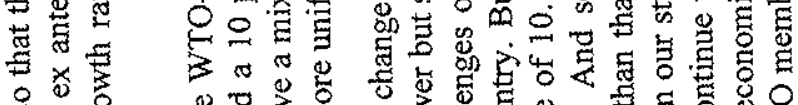

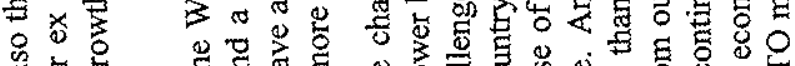

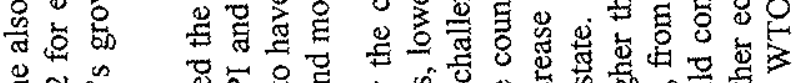

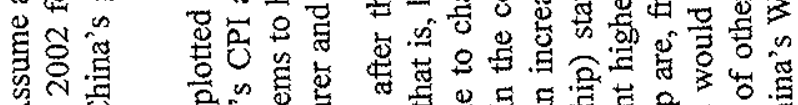

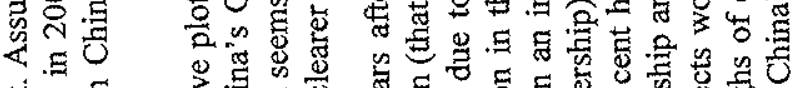

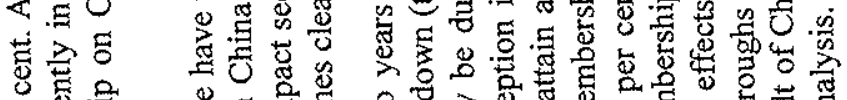

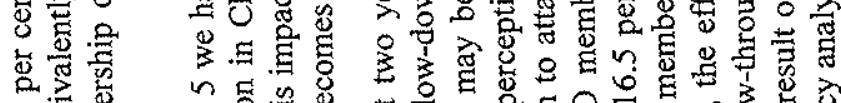

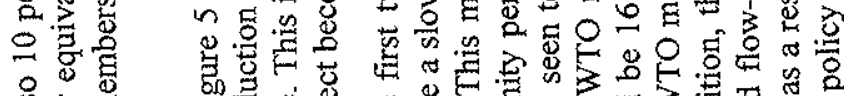

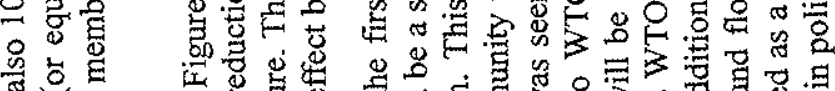

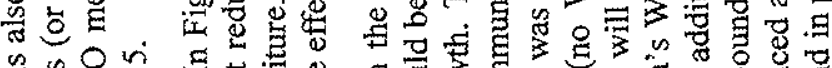

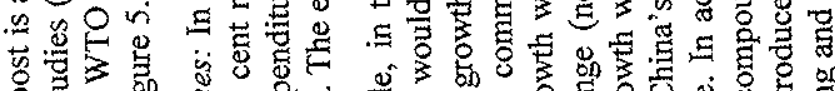

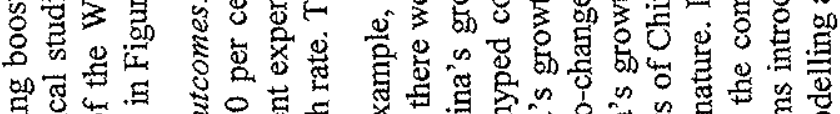

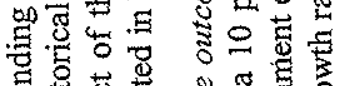

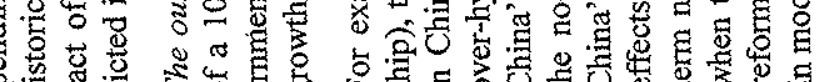

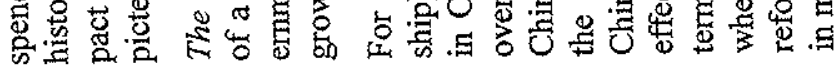

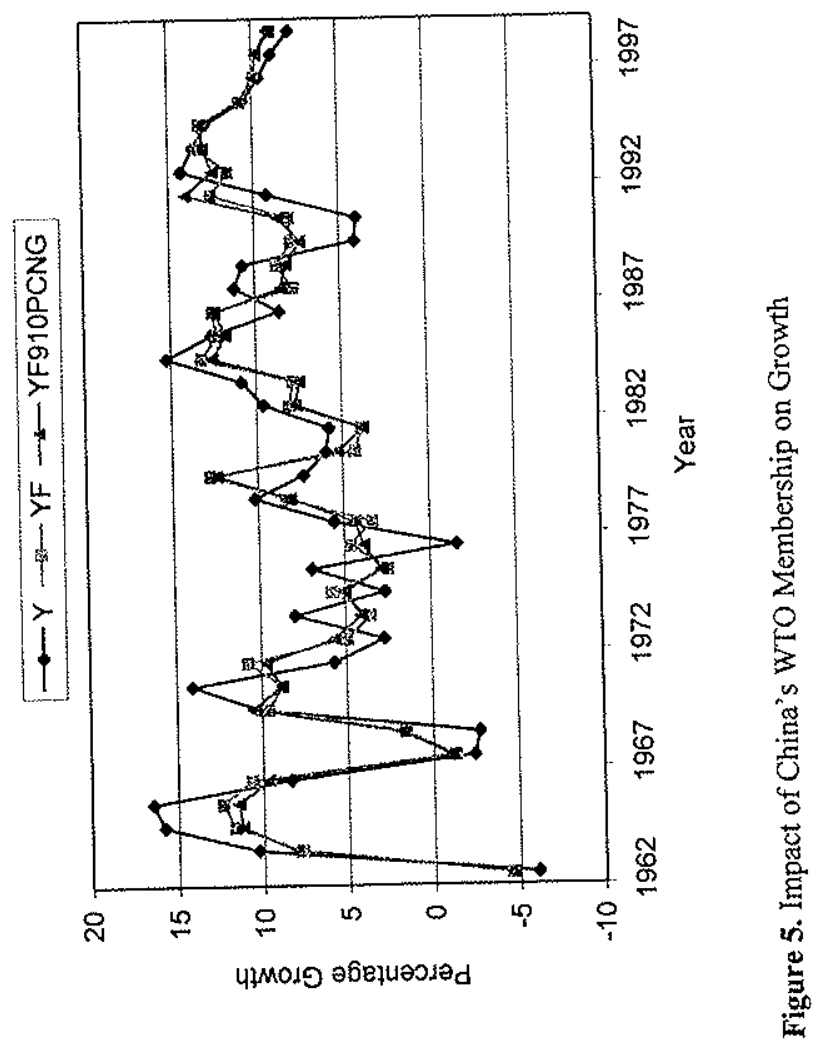

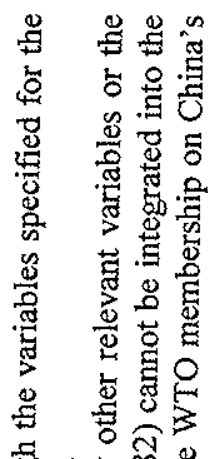

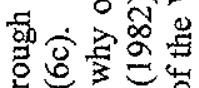

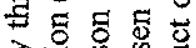

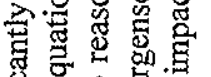

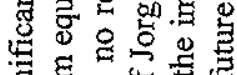

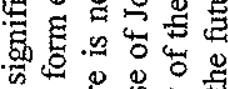

焉焉密.

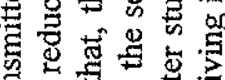

舟 5

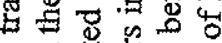

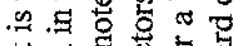

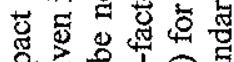

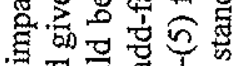

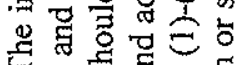

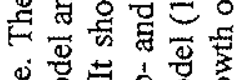

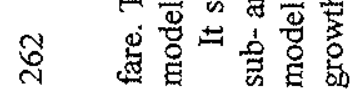

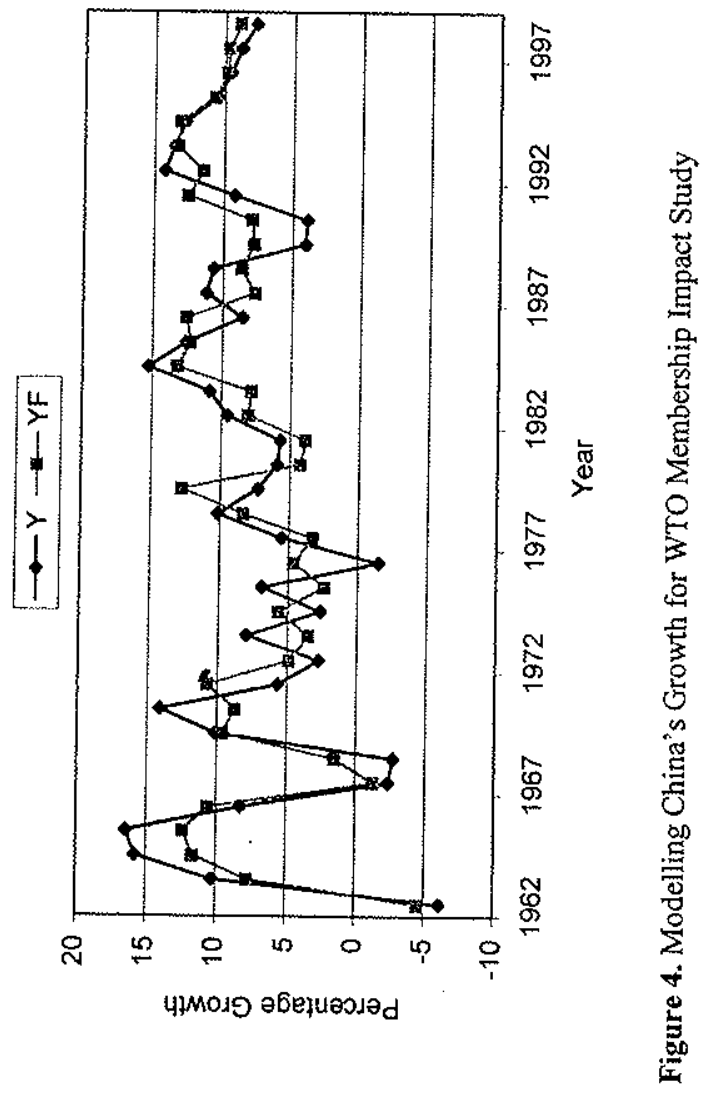

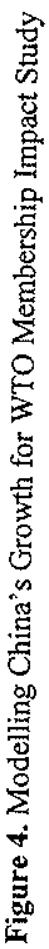

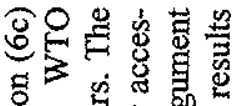

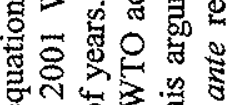

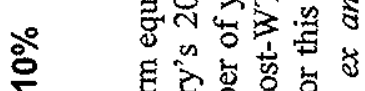

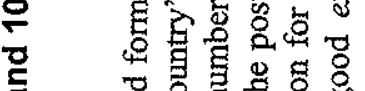

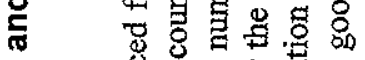

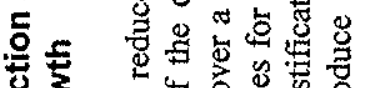

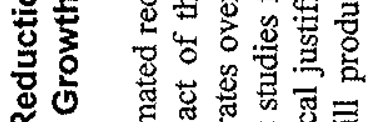

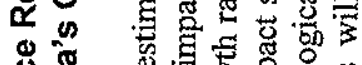

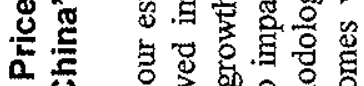

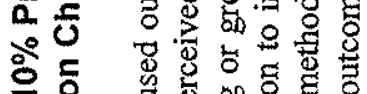

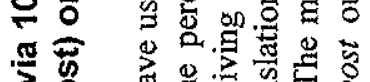

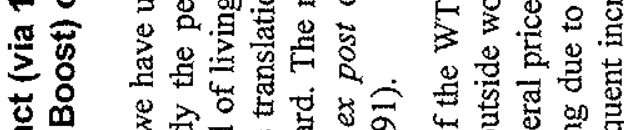

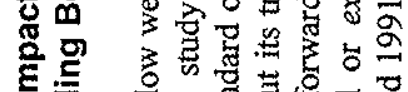

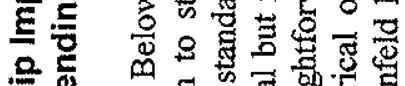

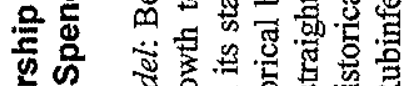

龸

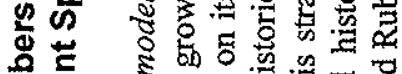

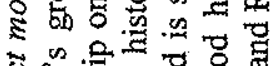

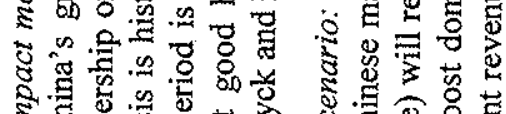

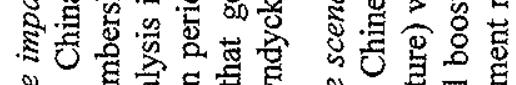

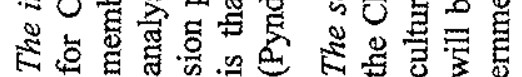




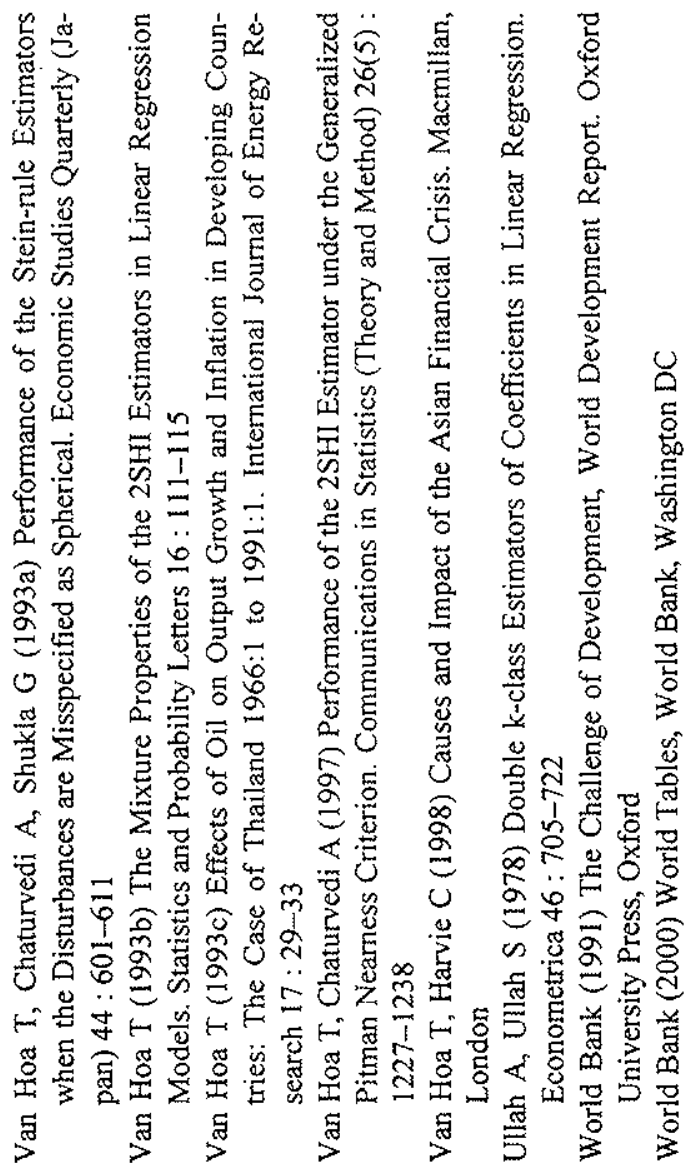

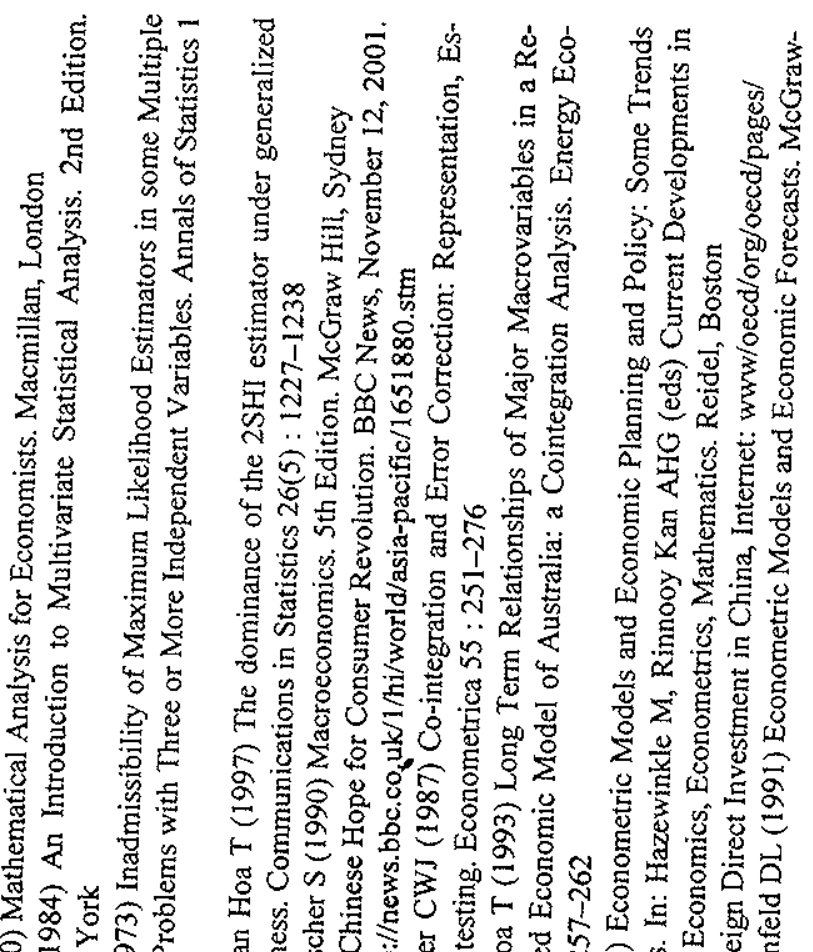

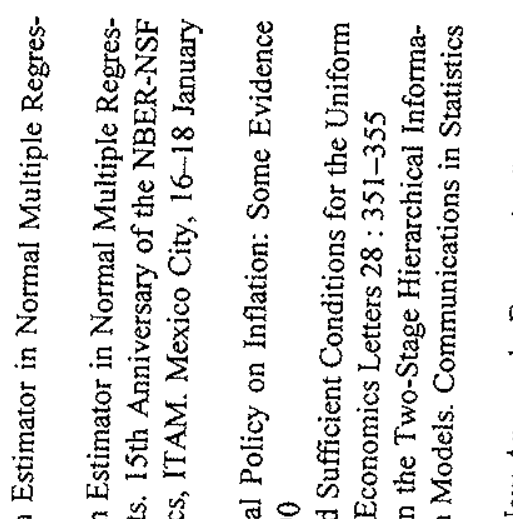

㟧 要击 类产焉

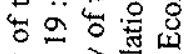

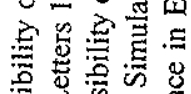

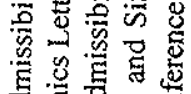
案言

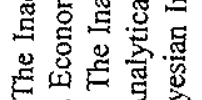

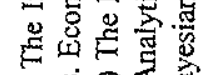

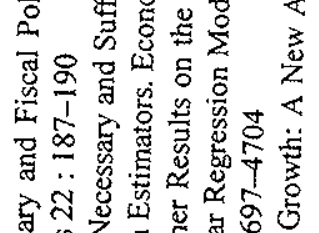

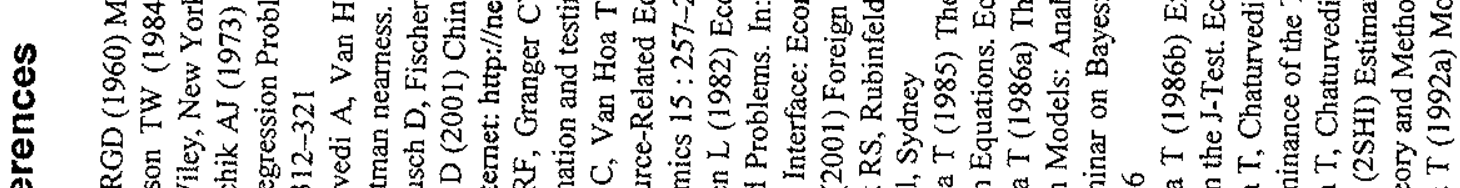

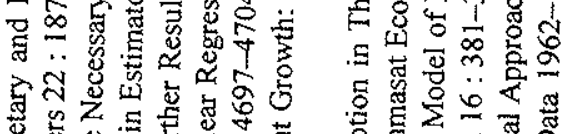

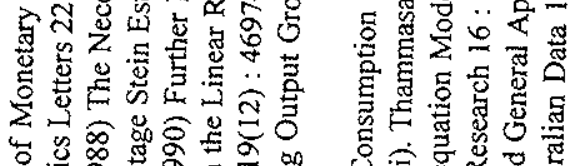

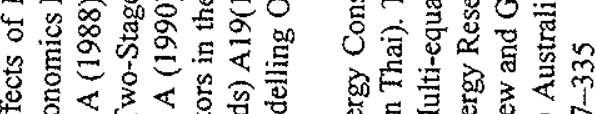

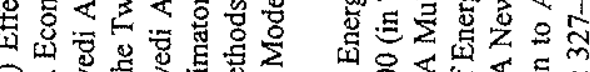

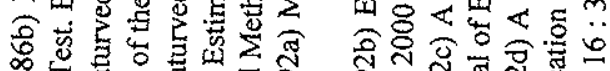

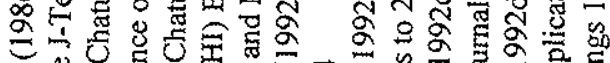

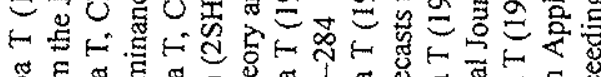

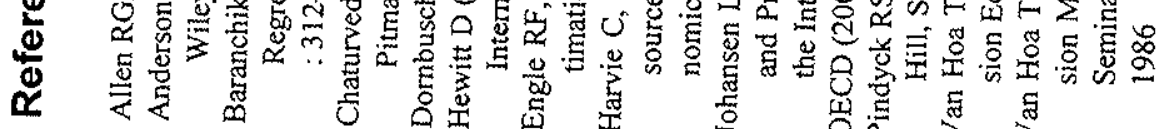

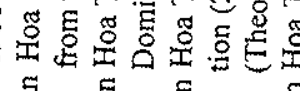
年 